\title{
Native and a Synthetic Analogue of the Malignancy-associated Parathyroid Hormone-like Protein Have In Vitro Transforming Growth Factor-like Properties
}

\author{
Karl L. Insogna, Andrew F. Stewart, Carol A. Morris, Lynn M. Hough, Leonard M. Milstone, and Michael Centrella \\ Department of Internal Medicine, Yale University School of Medicine, New Haven, Connecticut 06510; Departments of Internal \\ Medicine and Dermatology, West Haven Veterans Administration Medical Center, West Haven, Connecticut 06516; \\ and Endocrine Research, St. Frances Hospital and Medical Center, Hartford, Connecticut 06410
}

\begin{abstract}
A human parathyroid-like protein (PLP) has recently been isolated and cloned from human tumors associated with the paraneoplastic syndrome, humoral hypercalcemia of malignancy. PLP shares $\mathrm{NH}_{2}$-terminal amino acid sequence similarity with PTH but has a unique primary structure thereafter. Studies reported to date have indicated that both native and synthetic amino-terminal PLP polypeptides display actions in vivo and in vitro that are similar to those of PTH. We report here that purified native PLP and synthetic ${ }^{36} \mathrm{Tyr}(1-36)$ amide human PLP induce epidermal growth factor-dependent transformation of NRK 49F cells in soft agar. Further, the synthetic peptide induces a significant increase in the biosynthesis of fibronectin by human dermal fibroblasts. (1-34)PTH does not display either of these biological activities. These data indicate that there are qualitative differences between PTH and the recently identified PLP. The latter hormone appears to possess transforming growth factor-like properties that may be relevant to its physiological actions.
\end{abstract}

\section{Introduction}

Humoral hypercalcemia of malignancy $(\mathrm{HHM})^{1}$ is a paraneoplastic syndrome caused by the elaboration of a tumor-derived, bone-resorbing factor or factors (1). Recently, a PTHlike protein (PLP) has been isolated from several human and animal tumors associated with this syndrome (2-5). The circulating form of the PLP is not known, but proteins of $16,000-17,000$ and 6,000-9,000 kD have been isolated from extracts of malignant tissue or tumor cell-conditioned media (2-6). These forms share identical $\mathrm{NH}_{2}$-terminal amino acid sequences, suggesting that the two forms may arise by processing at the carboxy terminus. Full-length cDNA clones for the PLP have been identified that encode a 141 amino acid mature

Address correspondence to Dr. Karl L. Insogna, FMP 106, 333 Cedar Street, New Haven, CT 06510.

Received for publication 14 September 1988 and in revised form 22 November 1988.

1. Abbreviations used in this paper: EGF, epidermal growth factor; HDF, human dermal fibroblasts; HHM, humoral hypercalcemia of malignancy; PLP, PTH-like protein; TGF, transforming growth factor.

\section{J. Clin. Invest.}

(c) The American Society for Clinical Investigation, Inc.

$0021-9738 / 89 / 03 / 1057 / 04 \$ 2.00$

Volume 83, March 1989, 1057-1060 protein that shows considerable similarity with PTH in its first 13 amino acids but diverges completely in its primary structure thereafter $(7,8)$.

mRNAs encoding this protein have been identified in a variety of normal tissues (9). Furthermore, a similar PTH-like biological activity has been identified as a secretory product of normal human skin cells in culture (10). The physiological role of the peptide in these sites of expression is unknown.

Based on the deduced amino acid sequence for the PLP, biologically active amino-terminal polypeptide fragments have been synthesized, and a variety of initial reports describing their activities in vivo and in vitro have recently been published (11-16). In all of these studies, comparison has been made between PTH and the tumor-derived PLP. Taken together, these studies have demonstrated that while some quantitative differences in relative potency may exist between these two hormones, they display a qualitatively similar spectrum of activities in a variety of experimental systems. These studies have focused largely on the effects of these hormones in bone and renal tissues. Limited studies with native PLP have also reported qualitatively similar results for the two hormones (4).

Preliminary reports using crude or partially purified preparations of $\mathrm{HHM}$-associated tumors have suggested the presence of growth factor-like activities in these tumors (17-19). The relationship of these activities to the PTH-like biological activity present in these same tumors has remained unclear. The recent availability of purified native and a synthetic amino-terminal analogue of the PLP have allowed us to examine if this molecule displays transforming growth factor (TGF)-like activity.

\section{Methods}

Materials. The purified human PLP used in these studies represents a portion of that preparation described in the initial report of its purification (2). This 17,000-D protein was purified from $3.4 \mathrm{~g}$ of a breast carcinoma from a patient with HHM. The pure preparation was enriched 62,000-fold compared with the starting material and had a specific activity of $156 \mu \mathrm{geq} \mathrm{b}(1-34) \mathrm{PTH} / \mathrm{mg}$ protein (as determined in the intact bone cell cAMP accumulating assay using ROS 17/2.8 cells (2)). Synthetic ${ }^{36} \mathrm{Tyr}(1-36)$ amide human PLP was synthesized as previously described using solid phase techniques (14). Synthetic human (1-34)PTH was purchased from Bachem Inc., Torrance, CA. Aprotinin, leupeptin, phenylmethylsulfonylfluoride, and Triton X-100 were purchased from Sigma Chemical Co., St. Louis, MO. GelatinSepharose was purchased from Pharmacia Fine Chemicals (Piscataway, NJ). Porcine platelet-derived TGF- $\beta$ was purchased from R \& D Systems (Minneapolis, MN).

Soft agar transformation assay. The soft agar transformation assay was performed using NRK, clone $49 \mathrm{~F}$ cells, grown in DME containing 
$10 \%$ newborn calf serum as previously described (19). With this indicator cell line, epidermal growth factor (EGF) or TGF- $\alpha$ induce small $(<100 \mu \mathrm{m}$ diameter) colonies and TGF- $\beta$ alone fails to induce colony formation. With saturating (0.3-3.0 nM) levels of EGF, TGF- $\beta$ induces dose-dependent large colony formation $(>200 \mu \mathrm{m}$ diameter) which is maximal at $60-80 \%$ of total colony number (i.e., the percentage of all colonies formed that are large).

Fibronectin biosynthesis. Human dermal fibroblasts (HDF) were grown to confluence in six-well tissue culture plates as previously described (20). At confluence, cells were washed three times with serumfree DME and incubated for $12 \mathrm{~h}$ in the presence of agonists. After $12 \mathrm{~h}$ in culture cells were washed once with serum-free, methionine-free DME and incubated for $3 \mathrm{~h}$ with $1 \mathrm{ml}$ of the latter media containing the same concentrations of agonists plus $0.1 \mu \mathrm{Ci}$ of $\left[{ }^{35} \mathrm{~S}\right]$ methionine. At the end of $3 \mathrm{~h}$, media were harvested and fibronectin was purified using gelatin-Sepharose as described by others (21). Briefly, after harvesting media were placed on ice. To each $1 \mathrm{ml}$ of media was added $25 \lambda$ of $20 \% \mathrm{vol} / \mathrm{vol}$ Triton-X 100, $20 \lambda$ of $100 \mathrm{mM}$ PMSF, $10 \mu \mathrm{g}$ of aprotinin, $1 \mu \mathrm{g}$ of leupeptin, and $50 \lambda$ of gelatin Sepharose. After overnight agitation at $4^{\circ} \mathrm{C}$, the gelatin Sepharose beads were washed and suspended in sample buffer for SDS-PAGE. Gelatin Sepharose-purified proteins were separated by SDS-PAGE using a 5-10\% linear gradient of polyacrylamide. Fluorography was performed using an autoradiography enhancer (EN ${ }^{3}$ HANCE; New England Nuclear, Boston, MA) and preflashed X-ray film (X-AR5; Kodak, Rochester, NY). Densitometry readings were made on films exposed for $4 \mathrm{~h}$ using an electrophoresis image analyzer (Visage 2000; Bioimage Corp., Ann Arbor, MI). Cell number was determined using a Coulter counter (Coulter Electronics Inc., Hialeah, FL). Acid-insoluble radioactivity in the culture medium was determined by spotting filter paper with $5 \lambda$ of media followed by washing with TCA and scintillation counting.

Immunoblotting. For immunoblotting, separated proteins were transferred to a nitrocellulose sheet which was then washed, blocked for $60 \mathrm{~min}$ with gelatin in Tris-buffered saline, and transferred to a microseal bag with first antibody. First antibody was polyclonal goat anti-human fibronectin used at a dilution of 1:1,500 (Cappel Laboratories, Cochranville, PA). After overnight incubation at room temperature the membrane was exposed to second antibody which in this case was alkaline phosphatase-conjugated, affinity-purified rabbit anti-goat IgG used at a 1:3,000 dilution (Cappel Laboratories). Color development was achieved using nitroblue tetrazolium. Affinity-purified human plasma fibronectin was kindly supplied by Dr. Joseph Madri, Department of Pathology, Yale University School of Medicine (New Haven, CT).

\section{Results}

Effects of PLP and PTH in the transformation assay. The purified native PLP demonstrated dose-dependent transformation of NRK 49F cells as judged by anchorage-independent large colony formation (Fig. $1 A$ ). Limited amounts of this material precluded a more extensive dose-response curve, but at $\mathbf{0 . 3 0}$ nM 32\% large colony formation was noted. Initial studies with synthetic ${ }^{36} \mathrm{Tyr}(1-36)$ amide human PLP demonstrated that this polypeptide could also induce transformation in NRK 49F cells, with maximal transformation occurring in the $1 \mathrm{nM}$ range (Fig. $1 B$ ). In both cases this phenomenon occurred only in the presence of EGF. No large colonies were formed by either protein when EGF was omitted from the culture.

The activity of the synthetic analogue of PLP was examined in more detail and compared with that of PTH and TGF- $\beta$ in the soft agar assay. As shown in Fig. $2 A, 1$ nM EGF induced $13 \%$ large colony formation after $13 \mathrm{~d}$ of culture. In the presence of $1 \mathrm{nM}$ EGF, rat (1-34)PTH over a 10-fold dose range induced no significant additional large colony formation

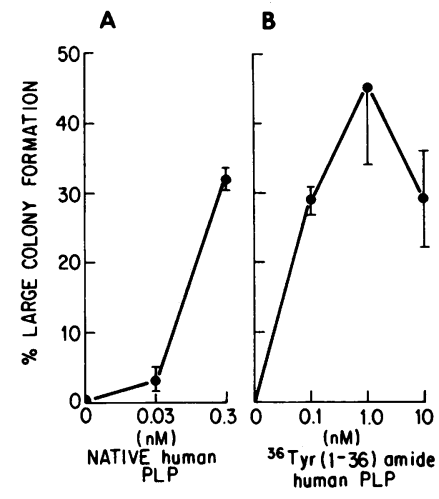

Figure 1. Induction of large colony formation by $(A)$ purified native human PLP and (B) synthetic ${ }^{36} \mathrm{Tyr}(1-36)$ amide human PTH-like peptide. $A$ shows that there is a dose-dependent increase in large colony formation induced by the native peptide. $B$ shows a biphasic response to the human synthetic peptide with maximal transformation induced at a concentration of $1 \mathrm{nM}$ and $45 \%$ colony induction. For $B$ the mean value at $1.0 \mathrm{nM}$ is significantly greater than the values at 0.1 or $10 \mathrm{nM}(P<0.05)$. In both experiments the data were analyzed after $13 \mathrm{~d}$ of culture. In both experiments there were no large colonies formed in the presence of EGF alone.

when compared with that produced by EGF alone. In contrast, synthetic ${ }^{36} \mathrm{Tyr}(1-36)$ amide human PTH-like peptide induced dose-dependent large colony formation that was detectable at $0.1 \mathrm{nM}$ and plateaued at $\sim 45 \%$ large colony formation in the dose range of 0.1 to $0.6 \mathrm{nM}$. TGF- $\beta$ was a more potent agonist in this assay and induced $49 \%$ large colony formation at 0.04 nM. Maximal large colony formation was seen at a TGF- $\beta$ concentration of $0.12 \mathrm{nM}$ which induced $65 \%$ large colony formation.

The rate at which induction of large colonies occurred over time was also different for TGF- $\beta$ and the synthetic PLP. As shown in Fig. $2 B$, at the highest concentration of factor tested, TGF- $\beta$ induced maximal large colony formation by $6 \mathrm{~d}$ of culture while the synthetic PLP showed a progressive induction of large colony formation over the $13 \mathrm{~d}$ of culture. PTH and EGF together caused a low-level induction of the large colony formation over time that was not significantly different from that induced by EGF alone.

Effects of PLP and PTH on fibronectin biosynthesis. In addition to induction of large colony formation by NRK 49F cells in soft agar, another characteristic property of TGF- $\beta$ is its ability to stimulate fibronectin secretion by fibroblasts (21). This effect has recently been observed in normal HDF (22). Since the human PLP appears to be made in skin (10) and

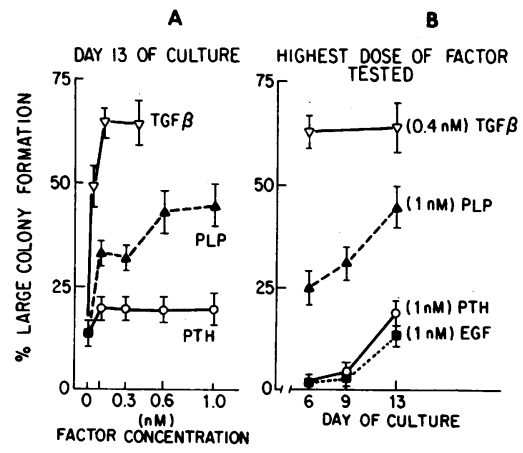

Figure 2. (A) The effect of increasing doses of human (1-34)PTH, ${ }^{36}$ Tyr(1-36)amide human PLP, and TGF- $\beta$ on induction of large colony formation. The data were analyzed after $13 \mathrm{~d}$ of culture. The values at $0.3,0.6$, and $1.0 \mathrm{nM}$ for the synthetic analogue of PLP are significantly different from the value at 0

nM. (B) The effect of the highest dose of factor tested on large colony formation in the presence of $1 \mathrm{nM}$ EGF read at days 6, 9, and 13 of culture. In all cases the assay was performed in the presence of $1 \mathrm{nM}$ EGF. Solid squares, percent large colony formation induced by $1 \mathrm{nM}$ EGF alone. 
stimulates cAMP accumulation in HDF (20), we examined whether it could stimulate fibronectin secretion by HDF.

As shown in Fig. 3, TGF- $\beta$ induced a significant increase in fibronectin biosynthesis by confluent fibroblasts. Under the experimental conditions used, TGF- $\beta$ induced a slight increase in total protein synthesis but no increase in cell number (Table I). PTH, by contrast, had no effect on fibronectin production and if anything slightly suppressed its biosynthesis. However, the human PLP caused a stimulation of fibronectin biosynthesis in a manner similar to TGF- $\beta$. Thus, as estimated by densitometry, the effect of synthetic PLP on fibronectin biosynthesis was twice that seen with PTH. PLP had no significant effect on total protein synthesis or cell number (Table I).

\section{Discussion}

These studies indicate that the tumor-derived PTH-like peptide has biological properties that are qualitatively distinct from those of PTH. PTH had no transforming activity on NRK 49F cells, while both native and the synthetic analogue of PLP induced significant anchorage-independent large colony formation in these cells. This effect occurred only in the presence of EGF, a biological property characteristic of, though not exclusive for, TGF- $\beta$. Thus, several other molecules including platelet-derived growth factor, retinoic acid, bovine brain-derived growth factor, and at least one other less well-characterized growth factor demonstrate EGF-dependent or -enhanced transformation of NRK cells (23-25). Our observations are of interest in view of the complete lack of structural similarity between TGF- $\beta$ and the human PLP based on comparison of amino acid sequences.

Relatively selective induction of fibronectin secretion in fibroblasts has been reported for TGF- $\beta$ (21). Some investigators have suggested that this effect may play a role in the ability of TGF- $\beta$ to induce anchorage-independent growth by certain cells (21). There has been little data reported on hormonal regulation of fibronectin biosynthesis. Glucocorticoids and insulin-like growth factor II also increase fibronectin synthesis although with the latter this is part of a generalized increase in protein synthesis $(21,26)$. In contrast, fibroblast growth factor

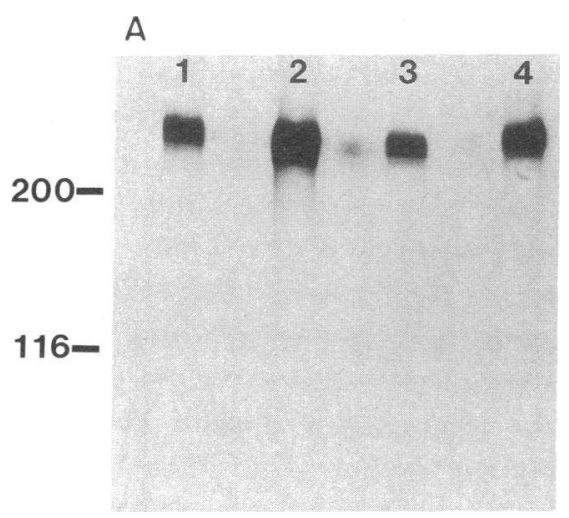

B

Figure 3. (A) Fluorogram of radio-labeled fibronectin secreted into the culture medium by confluent human dermal fibroblasts. Lane 1 , control; lane 2 , TGF- $\beta\left(5 \times 10^{-10} \mathrm{M}\right)$; lane 3, human (1-34)PTH (5 $\left.\times 10^{-9} \mathrm{M}\right)$; lane 4, human ${ }^{36} \mathrm{Tyr}(1-36)$ amide PLP $\left(5 \times 10^{-9} \mathrm{M}\right) .(B)$ Immunoblot of HDF-derived fibronectin. Lane 1 , fibronectin prepared from HDF as in $(A)$; lane $2,1.3 \mu \mathrm{g}$ of fibronectin standard.
Table I. Effect of Media Alone, TGF- $\beta\left(5 \times 10^{-10} \mathrm{M}\right)$; Human $(1-34) P T H\left(5 \times 10^{-9} M\right)$, or Synthetic Human PLP $\left(5 \times 10^{-10}\right.$ $M)$ on Cell Number, and Acid-insoluble Radioactivity Secreted into the Culture Media

\begin{tabular}{lcc}
\hline & No. of cells/cm & $\begin{array}{c}\text { Acid-insoluble } \\
\text { cpm per } 5 \lambda \text { of } \\
\text { media }\end{array}$ \\
\hline Control & $36,000 \pm 3,200$ & $4,200 \pm 1,200$ \\
TGF- $\beta$ & $31,200 \pm 1,300$ & $6,300 \pm 1,200^{*}$ \\
PTH & $33,000 \pm 3,200$ & $3,900 \pm 100$ \\
${ }^{36}$ Tyr(1-36)amide PLP & $32,300 \pm 4,300$ & $3,800 \pm 200$ \\
\hline
\end{tabular}

Confluent HDF were exposed to agonist for $15 \mathrm{~h}$ in serum-free DME. For the last $3 \mathrm{~h}$ of the experiment $0.1 \mu \mathrm{Ci}$ of $\left[{ }^{35} \mathrm{~S}\right]$ methionine was added in serum-free, methionine-free DME with the same concentrations of agonists.

* $P<0.05$ compared with the control value.

and EGF have no effect in fibronectin biosynthesis (21). The mechanism by which the PLP induces transformation and stimulates fibronectin biosynthesis in fibroblasts is not clear. It is possible that occupancy of a receptor that also binds TGF- $\beta$ represents one mechanism by which these effects are induced. Whether a separate class of receptors distinct from those for PTH or TGF- $\beta$ exists for PLP remains to be determined.

Our transformation time-course studies indicate that PLP induces transformation at a slower rate than TGF- $\beta$ and plateaus at a lower level of total large colonies formed. Similarly, the effect on fibronectin biosynthesis is somewhat less prominent with the human PLP. This may simply reflect differences in potency or more fundamental differences in mechanisms of induction of these biological activities.

The TGF-like properties of PLP may have some relevance to its physiological mechanism of action. As noted earlier, we have recently reported the presence of PLP or a very similar molecule in cultures of human keratinocytes (10). TGF- $\beta$ has been shown to exhibit potent effects in skin and it is therefore possible that the PTH-like peptide plays an autocrine or paracrine role in normal skin homeostasis through its TGF-like properties. Further exploration of the growth factor-like properties of this molecule should lead to a broader view of its mechanism of action in a variety of normal tissues.

\section{Acknowledgments}

We thank Mrs. Nancy Canetti for preparing the manuscript.

This work was supported by grants from the Veterans Administration and the National Institutes of Health.

\section{References}

1. Insogna, K. L., and A. E. Broadus. 1987. Hypercalcemia of malignancy. Annu. Rev. Med. 38:241-245.

2. Burtis, W. J., T. Wu, C. Bunch, J. J. Wysolmerski, K. L. Insogna, E. C. Weir, A. E. Broadus, and A. F. Stewart. 1987. Identification of a novel 17,000-parathyroid hormone-like adenylate cyclase-stimulating protein from a tumor associated with humoral hypercalcemia of malignancy. J. Biol. Chem. 262:7151-7156.

3. Moseley, J. M., M. Kubota, H. Diefenbach-Jagger, R. E. H. Wettenhall, B. E. Kemp, L. J. Suva, C. P. Rodda, P. R. Ebeling, P. J. Hudson, J. D. Zajac, and T. J. Martin. 1987. Parathyroid hormonerelated protein purified from a human lung cancer cell line. Proc. Natl. Acad. Sci. USA. 84:5048-5052. 
4. Strewler, G. J., P. H. Stern, J. W. Jacobs, J. Eveloff, R. F. Klein, S. C. Leung, M. Rosenblatt, and R. Nissenson. 1987. Parathyroid hormone-like protein from human renal carcinoma cells structural and functional homology with parathyroid hormone. J. Clin. Invest. 80:1803-1807.

5. Weir, E., W. Burtis, C. Morris, T. Brady, and K. Insogna. 1988. Isolation of 16,000 dalton parathyroid hormone-like proteins from two animal tumors causing humoral hypercalcemia of malignancy. Endocrinology. 123:2744-2751.

6. Stewart, A. F., T. Wu, D. Goumas, W. J. Burtis, and A. E. Broadus. 1987. N-terminal amino acid sequence of two novel tumorderived adenylate cyclase-stimulating proteins: identification of parathyroid hormone-like and parathyroid hormone-unlike domains. Biochem. Biophys. Res. Commun. 146:672-678.

7. Suva, L. J., G. A. Winslow, R. E. H. Wettenhall, G. R. C. Hammonds, J. M. Moseley, H. Diefenbach-Jagger, C. P. Rodda, B. E. Kemp, H. Rodriques, E. Y. Chen, P. J. Hudson, T. J. Martin, and W. I. Wood. 1987. A parathyroid hormone-related protein implicated in malignant hypercalcemia: cloning and expression. Science (Wash. DC). 237:893-896.

8. Mangin, M., A. C. Webb, B. E. Dreyer, J. T. Posillico, K. Ikeda, E. C. Weir, A. F. Stewart, N. H. Bander, L. M. Milstone, D. E. Barton, U. Francke, and A. E. Broadus. 1988. Identification of a cDNA encoding a parathyroid hormone-like peptide from a human tumor associated with humoral hypercalcemia of malignancy. Proc. Natl. Acad. Sci. USA. 85:597-601.

9. Ikeda, K., E. Weir, M. Mangin, P. Dannies, B. Kinder, L. Deftos, E. Brown, and A. Broadus. 1988. Expression of messenger RNAs encoding a parathyroid hormone-like peptide in normal human and animal tissues with abnormal expression in human parathyroid adenomas. Mol. Endocrinol. 2:1230-1236.

10. Merendino, J J., K. L. Insogna, L. M. Milstone, A. E. Broadus, and A. F. Stewart. 1986. Cultured human keratinocytes produce a parathyroid hormone-like protein. Science (Wash DC). 231:388-390.

11. Winquist, R. J., E. P. Baskin, and G. P. Vlausk. 1987. Synthetic tumor-derived human hypercalcemia factor exhibits parathyroid hormone-like vasorelaxation in renal arteries. Biochem. Biophys. Res. Commun. 149:227-237.

12. Horiuchi, N., M. P. Caulfield, J. E. Fisher, M. E. Goldman, R. L. McKee, J. E. Regan, J. J. Levy, R. F. Nutt, S. B. Rodan, T. L. Shofield, T. L. Clemens, and M. Rosenblatt. 1987. Similarity of synthetic peptide from human tumor to parathyroid hormone in vivo and in vitro. Science (Wash. DC). 238:1566-1568.

13. Kemp, B. E., J. M. Moseley, C. P. Rodda, P. R. Ebeling, R. E. H. Wettenhall, D. Stapleton, H. Dieffenbach-Jagger, F. Ure, V. P. Michelangeli, H. A. Simmons, L. G. Raisz, and T. J. Martin. 1987. Parathyroid hormone-related protein of malignancy: active synthetic fragments. Science (Wash. DC). 238:1568-1570.

14. Stewart, A. F., M. Mangin, T. Wu, D. Goumas, K. L. Insogna, W. J. Burtis, and A. E. Broadus. 1988. Synthetic human parathyroid hormone-like protein stimulates bone resorption and causes hypercalcemia in rats. J. Clin. Invest. 81:596-600.
15. Sartori, L., E. C. Weir, A. F. Stewart, A. E. Broadus, M. Mangin, P. Q. Barrett, and K. L. Insogna. 1988. Synthetic and partially-purified adenylate cyclase-stimulating proteins from tumors associated with humoral hypercalcemia of malignancy inhibit phosphate transport in a PTH-responsive renal cell line. J. Clin. Endocrinol. Metab. 66:459-461.

16. Rodan, S., M. Noda, G. Wesolowski, M. Rosenblatt, and G. A. Rodan. 1988. Comparison of postreceptor effects of 1-34 human hypercalcemia factor and 1-34 human parathyroid hormone in rat osteosarcoma cells. J. Clin. Invest. 81:924-927.

17. Ibbotson, K. J., S. M. D’Souza, K. W. Ng, C. K. Osborne, T. J. Martin, and G. R. Munch. 1983. Tumor derived growth factor increases bone resorption in a tumor associated with humoral hypercalcemia of malignancy. Science (Wash. DC). 221:1292-1294.

18. Mundy, G. R., K. J. Ibbotson, S. M. D’Souza, S. C. Kukrega, E. C. Abramson, L. J. Kukla, G. Carpenter, and R. Derynck. 1985. Evidence that transforming growth factor alpha production causes bone resorption and hypercalcemia in squamous cell carcinoma of the lung. Clin. Res. 33:573A. (Abstr.)

19. Insogna, K. L., E. C. Weir, T. L. Wu, A. F. Stewart, A. E. Broadus, W. J. Burtis, and M. Centrella. 1987. Co-purification of transforming growth factor beta-like activity with PTH-like and boneresorbing activities from a tumor associated with humoral hypercalcemia of malignancy. Endocrinology. 120:2183-2185.

20. Wu, T. L., K. L. Insogna, L. M. Hough, L. Milstone, and A. F. Stewart. 1987. Skin-derived fibroblasts respond to human parathyroid hormone-like adenylate cyclase-stimulating proteins. J. Clin. Endocrinol. Metab. 65:105-109.

21. Ignotz, R. A., and J. Massague. 1986. Transforming growth factor- $\beta$ stimulates the expression of fibronectin and collagen and their incorporation into the extracellular matrix. J. Biol. Chem. 261:43374345.

22. Raghow, R., A. E. Postlethwaite, J. Keski-Oja, H. L. Moses, and A. H. Kang. 1987. Transforming growth factor- $\beta$ increases steady state levels of type I procollagen and fibronectin messenger RNAs posttranscriptionally in cultured human dermal fibroblasts. J. Clin. Invest. 79:1285-1288.

23. van Zoelen, E. J. J., T. M. J. van Oostwaard, and S. W. de Laat. 1986. Transforming growth factor- $\beta$ and retinoic acid modulate phenotypic transformation of normal rat kidney cells induced by epidermal growth factor and platelet-derived growth factor. J. Biol. Chem. 261:5003-5009.

24. Huang, S. S., M. D. Kuo, and J. S. Huang. 1986. Transforming growth factor activity of bovine brain-derived growth factor. Biochem. Biophys. Res. Commun. 136:619-625.

25. Tucker, R. F., M. E. Volkenant, E. L. Branum, and H. L. Moses. 1983. Comparison of intra- and extracellular transforming growth factors from nontransformed and chemically transformed mouse embryo cells. Cancer Res. 43:1581-1586.

26. Oliver, N., R. F. Newby, L. T. Furcht, and S. Bourgeois. 1983. Regulation of fibronectin biosynthesis by glucocorticoids in human fibrosarcoma cells and normal fibroblasts. 1983. Cell. 33:287-296. 